\title{
Some results on parallel iterative algorithms for strictly pseudocontractive mappings
}

Xiaoye Yang ${ }^{1}$, Yuan Qing ${ }^{2}$ and Mingliang Zhang ${ }^{3 *}$

\section{${ }^{*}$ Correspondence:}

hdzhangml@yeah.net

${ }^{3}$ Department of Mathematics,

Henan University, Kaifeng, China

Full list of author information is

available at the end of the article

\begin{abstract}
In this paper, a parallel iterative algorithm with mixed errors is investigated. Strong and weak convergence theorems of common fixed points of a finite family of strictly pseudocontractive mappings are established in a real Banach space.
\end{abstract}

AMS Subject Classification: 47H05; 47H09; 47J25

Keywords: implicit iterative algorithm; fixed point; pseudocontractive mapping; strictly pseudocontractive mapping

\section{Introduction and preliminaries}

Throughout this paper, we denote by $E$ and $E^{*}$ a real Banach space and a dual space of $E$, respectively. Let $\langle\cdot, \cdot\rangle$ denote the pairing between $E$ and $E^{*}$. The normalized duality mapping $J: E \rightarrow 2^{E^{*}}$ is defined by

$$
J(x)=\left\{f \in E^{*}:\langle x, f\rangle=\|x\|^{2}=\|f\|^{2}\right\}, \quad \forall x \in E .
$$

In the sequel, we use $j$ to denote the single-valued normalized duality mapping. Let $K$ be a nonempty subset of $E$ and $T: K \rightarrow K$ be a mapping. Recall the following.

$T$ is said to be Lipschitz if there exists a positive constant $L$ such that

$$
\|T x-T y\| \leq L\|x-y\|, \quad \forall x, y \in K .
$$

$T$ is said to be nonexpansive if

$$
\|T x-T y\| \leq\|x-y\|, \quad \forall x, y \in K .
$$

$T$ is said to be strictly pseudocontractive in the terminology of Browder and Petryshyn [1] if there exists $\lambda>0$ such that

$$
\langle T x-T y, j(x-y)\rangle \leq\|x-y\|^{2}-\lambda\|(x-T x)-(y-T y)\|^{2}, \quad \forall x, y \in K,
$$

for some $j(x-y) \in J(x-y)$. It is clear that the class of strictly pseudocontractive mappings includes the class of nonexpansive mappings as a special case. It is also clear that (1.1) is equivalent to the following:

$$
\left\langle(I-T) x-\left(I_{T}\right) y, j(x-y)\right\rangle \geq \lambda\|(I-T) x-(I-T) y\|^{2}, \quad \forall x, y \in K .
$$

@ 2013 Yang et al.; licensee Springer. This is an Open Access article distributed under the terms of the Creative Commons Attribution License (http://creativecommons.org/licenses/by/2.0), which permits unrestricted use, distribution, and reproduction in any medium, provided the original work is properly cited. 
We know that strictly pseudocontractive mappings are Lipschitz continuous. Indeed, we find from (1.2) that

$$
\|T x-T y\| \leq \frac{1+\lambda}{\lambda}\|x-y\|, \quad \forall x, y \in K
$$

$T$ is said to be strongly pseudocontractive if there exists $k \in(0,1)$ such that

$$
\langle T x-T y, j(x-y)\rangle \leq k\|x-y\|^{2}, \quad \forall x, y \in K,
$$

for some $j(x-y) \in J(x-y) . T$ is said to be pseudocontractive if there exists some $j(x-y) \in$ $J(x-y)$ such that

$$
\langle T x-T y, j(x-y)\rangle \leq\|x-y\|^{2}, \quad \forall x, y \in K .
$$

$T$ is said to be Lipschitz if there exists a positive constant $L$ such that

$$
\|T x-T y\| \leq L\|x-y\|, \quad \forall x, y \in K .
$$

It is well known that [2] (1.4) is equivalent to the following:

$$
\|x-y\| \leq\|x-y+s[(I-T) x-(I-T) y]\|, \quad \forall s>0 .
$$

We remark that the class of strongly pseudocontractive mappings is independent of the class of strictly pseudocontractive mappings. This can be seen from the following examples.

Example 1.1 [3] Take $K=(0, \infty)$ and define $T: K \rightarrow K$ by

$$
T x=\frac{x^{2}}{1+x} .
$$

Then $T$ is a strictly pseudocontractive mapping but not a strongly pseudocontractive mapping.

Example 1.2 [3] Take $K=R$ and define $T: K \rightarrow K$ by

$$
T x= \begin{cases}1, & x \in(-\infty,-1), \\ \sqrt{1-(1+x)^{2}}, & x \in[-1,0), \\ -\sqrt{1-(x-1)^{2}}, & x \in[0,1], \\ 1, & x \in(1, \infty) .\end{cases}
$$

Example 1.3 [4] Take $E=R^{2}, B=\left\{x \in R^{2}:\|x\| \leq 1\right\}, B_{1}=\left\{x \in B:\|x\| \leq \frac{1}{2}\right\}, B_{2}=\{x \in B$ : $\left.\frac{1}{2} \leq\|x\| \leq 1\right\}$. If $x=(a, b) \in E$, we define $x^{\perp}$ to be $(b,-a) \in E$. Define $T: B \rightarrow B$ by

$$
T x= \begin{cases}x+x^{\perp}, & x \in B_{1}, \\ \frac{x}{\|x\|}-x+x^{\perp}, & x \in B_{2} .\end{cases}
$$


Then $T$ is a Lipschitz pseudocontractive mapping but not a strictly pseudocontractive mapping.

Let $U=\{x \in E:\|x\|=1\}$. $E$ is said to be smooth or is said to have a Gâteaux differentiable norm if the limit

$$
\lim _{t \rightarrow 0} \frac{\|x+t y\|-\|x\|}{t}
$$

exists for each $x, y \in U$. $E$ is said to have a uniformly Gâteaux differentiable norm if for each $y \in U$, the limit is attained uniformly for all $x \in U$. $E$ is said to be uniformly smooth or is said to have a uniformly Fréchet differentiable norm if the limit is attained uniformly for $x, y \in U$. It is known that if the norm of $E$ is uniformly Gâteaux differentiable, then the duality mapping $J$ is single valued and uniformly norm to weak* continuous on each bounded subset of $E$.

In 2001, Xu and Ori [5], in the framework of Hilbert spaces, introduced the following implicit iteration process for a finite family of nonexpansive mappings $\left\{T_{1}, T_{2}, \ldots, T_{N}\right\}$ with $\left\{\alpha_{n}\right\}$ a real sequence in $(0,1)$ and an initial point $x_{0} \in C$ :

$$
\begin{aligned}
& x_{1}=\alpha_{1} x_{0}+\left(1-\alpha_{1}\right) T_{1} x_{1}, \\
& x_{2}=\alpha_{2} x_{1}+\left(1-\alpha_{2}\right) T_{2} x_{2}, \\
& \cdots \\
& x_{N}=\alpha_{N} x_{N-1}+\left(1-\alpha_{N}\right) T_{N} x_{N}, \\
& x_{N+1}=\alpha_{N+1} x_{N}+\left(1-\alpha_{N+1}\right) T_{1} x_{N+1}, \\
& \cdots
\end{aligned}
$$

which can written in the following compact form:

$$
x_{n}=\alpha_{n} x_{n-1}+\left(1-\alpha_{n}\right) T_{n} x_{n}, \quad \forall n \geq 1,
$$

where $T_{n}=T_{n(\bmod N)}$ (here the $\bmod N$ takes values in $\left.\{1,2, \ldots, N\}\right)$.

They obtained the following weak convergence theorem.

Theorem XO Let $H$ be a real Hilbert space, $K$ be a nonempty closed convex subset of $H$, and $T_{i}: K \rightarrow K$ be a nonexpansive mapping such that $F=\bigcap_{i=1}^{N} F\left(T_{i}\right) \neq \emptyset$. Let $\left\{x_{n}\right\}$ be defined by (1.6). If $\left\{\alpha_{n}\right\}$ is chosen so that $\alpha_{n} \rightarrow 0$ as $n \rightarrow \infty$, then $\left\{x_{n}\right\}$ converges weakly to a common fixed point of the family of $\left\{T_{i}\right\}_{i=1}^{N}$.

They further remarked that it is yet unclear what assumptions on the mappings and/or the parameters $\left\{\alpha_{n}\right\}$ are sufficient to guarantee the strong convergence of the sequence $\left\{x_{n}\right\}$.

In 2004, Osilike [6] further extended the above results from Hilbert spaces to Banach spaces. To be more precise, he obtain the following results.

Theorem $\mathbf{O}$ Let $H$ be a real Hilbert space, $K$ be a nonempty closed convex subset of $H$, and $T_{i}: K \rightarrow K$ be a strictly pseudocontractive mapping such that $F=\bigcap_{i=1}^{N} F\left(T_{i}\right) \neq \emptyset$. Let $\left\{x_{n}\right\}$ 
be defined by (1.6). If $\left\{\alpha_{n}\right\}$ is chosen so that $\alpha_{n} \rightarrow 0$ as $n \rightarrow \infty$, then $\left\{x_{n}\right\}$ converges weakly to a common fixed point of the family of $\left\{T_{i}\right\}_{i=1}^{N}$.

Subsequently, many authors have investigated the fixed point problem of strictly pseudocontractive mappings based on an implicit or non-implicit iterative algorithm in Banach spaces; see [7-32] and the references therein.

In 2007, Acedo and Xu proposed a parallel iterative algorithm for strictly pseudocontractive mappings in the framework of Hilbert spaces. Weak and strong convergence theorems for common fixed points of a family of strictly pseudocontractive mappings were established; see [26] for more details and the reference therein.

In this paper, motivated by the above results, we consider an implicitly parallel iterative algorithm for a finite family of strictly pseudocontractive mappings. Weak and strong convergence theorems are established in the framework of Banach spaces.

In order to prove our main results, we need the following conceptions and lemmas.

Recall that the space $E$ is said to satisfy Opial's condition [33] if, for each sequence $\left\{x_{n}\right\}$ in $E$, the convergence $x_{n} \rightarrow x$ weakly implies that

$$
\liminf _{n \rightarrow \infty}\left\|x_{n}-x\right\|<\liminf _{n \rightarrow \infty}\left\|x_{n}-y\right\|, \quad \forall y \in E(y \neq x) .
$$

Recall that the mapping $T: K \rightarrow K$ is semicompact if any sequence $\left\{x_{n}\right\}$ in $K$ satisfying $\lim _{n \rightarrow \infty}\left\|x_{n}-T x_{n}\right\|=0$ has a convergent subsequence.

Lemma 1.1 [34] Let E be a real Banach space, $K$ be a nonempty closed convex subset of $E$, and $T: K \rightarrow K$ be a continuous strongly pseudocontractive mapping. Then $T$ has a unique fixed point in $K$.

Lemma 1.2 [11] Let E be a smooth Banach space and $K$ be a nonempty convex subset of $E$. Let $r \geq 1$ be some integer. Let $T_{i}: K \rightarrow K$ be a strictly pseudocontractive mapping. Assume that $\bigcap_{i=1}^{r} F\left(T_{i}\right)$ is not empty. Assume that $\left\{\mu_{i}\right\}_{i=1}^{r}$ is a positive sequence such that $\sum_{i=1}^{r} \mu_{i}=1$. Then $\bigcap_{i=1}^{r} F\left(T_{i}\right)=F\left(\sum_{i=1}^{r} \mu_{i} T_{i}\right)$.

Lemma 1.3 [35] Let $\left\{a_{n}\right\},\left\{b_{n}\right\}$, and $\left\{c_{n}\right\}$ be three nonnegative sequences satisfying the following condition:

$$
a_{n+1} \leq\left(1+b_{n}\right) a_{n}+c_{n}, \quad \forall n \geq n_{0}
$$

where $n_{0}$ is some nonnegative integer, $\sum_{n=1}^{\infty} b_{n}<\infty$, and $\sum_{n=1}^{\infty} c_{n}<\infty$. Then the limit $\lim _{n \rightarrow \infty} a_{n}$ exists.

\section{Main results}

Theorem 2.1 Let E be a smooth and reflexive Banach space which also satisfies Opial's condition and $K$ be a nonempty closed convex subset of E. Let $N \geq 1$ be some positive integer. Let $T_{m}: K \rightarrow K$, where $m \in\{1, \ldots, N\}$, be a $\lambda_{i}$-strictly pseudocontractive mapping and $\left\{u_{n}\right\}$ be a bounded sequence in $K$. Let $\left\{x_{n}\right\}_{n=0}^{\infty}$ be a sequence generated in the following algorithm:

$$
x_{0} \in K, \quad x_{n}=\alpha_{n} x_{n-1}+\beta_{n} \sum_{m=1}^{N} \delta_{m} T_{m} x_{n}+\gamma_{n} u_{n}, \quad n \geq 1,
$$


where $\left\{\alpha_{n}\right\},\left\{\beta_{n}\right\},\left\{\gamma_{n}\right\}$, and $\left\{\delta_{m}\right\}$ are real number sequences in $[0,1]$. Assume that $F:=$ $\bigcap_{m=1}^{N} F\left(T_{m}\right) \neq \emptyset$, and the above control sequences satisfy the following restrictions:

(a) $\sum_{m=1}^{N} \delta_{m}=\alpha_{n}+\beta_{n}+\gamma_{n}=1$;

(b) $\sum_{n=1}^{\infty} \gamma_{n}<\infty$;

(c) $0<a \leq \alpha_{n} \leq b<1$, where $a$ and $b$ are constants.

Then $\left\{x_{n}\right\}$ converges weakly to some point in $F$.

Proof Put $T:=\sum_{m=1}^{N} \delta_{m} T_{m}$. We show that $T$ is $\lambda$-strictly pseudocontractive mapping, where $\lambda:=\min \left\{\lambda_{m}: 1 \leq m \leq N\right\}$. Notice that

$$
\begin{aligned}
\langle T x- & T y, j(x-y)\rangle \\
= & \delta_{1}\left\langle T_{1} x-T_{1} y, j(x-y)\right\rangle+\delta_{2}\left\langle T_{2} x-T_{2} y, j(x-y)\right\rangle+\cdots \\
& +\delta_{N}\left\langle T_{N} x-T_{N} y, j(x-y)\right\rangle \\
\leq & \delta_{1}\left(\|x-y\|^{2}-\lambda_{1}\left\|\left(I-T_{1}\right) x-\left(I-T_{1}\right) y\right\|^{2}\right) \\
& +\delta_{2}\left(\|x-y\|^{2}-\lambda_{2}\left\|\left(I-T_{2}\right) x-\left(I-T_{2}\right) y\right\|^{2}\right)+\cdots \\
& +\delta_{N}\left(\|x-y\|^{2}-\lambda_{N}\left\|\left(I-T_{N}\right) x-\left(I-T_{N}\right) y\right\|^{2}\right) \\
\leq & \|x-y\|^{2}-\lambda\left(\delta_{1}\left\|\left(I-T_{1}\right) x-\left(I-T_{1}\right) y\right\|^{2}\right. \\
& +\delta_{2}\left\|\left(I-T_{2}\right) x-\left(I-T_{2}\right) y\right\|^{2}+\cdots \\
& \left.+\delta_{N}\left\|\left(I-T_{N}\right) x-\left(I-T_{N}\right) y\right\|^{2}\right) \\
\leq & \|x-y\|^{2}-\lambda\|(I-T) x-(I-T) y\|^{2} .
\end{aligned}
$$

This proves that $T$ is $\lambda$-strictly pseudocontractive mapping. Next, we show that the implicit iterative algorithm (2.1) is well defined for the strictly pseudocontractive mappings. Define a mapping

$$
P_{n}(x)=\alpha_{n} x_{n-1}+\beta_{n} \sum_{m=1}^{N} \delta_{m} T_{m} x+\gamma_{n} u_{n}, \quad \forall n \geq 1
$$

It follows that

$$
\begin{aligned}
& \left\langle P_{n}(x)-P_{n}(y), j(x-y)\right\rangle \\
& =\beta_{n}\left\langle\sum_{m=1}^{N} \delta_{m} T_{m} x-\sum_{m=1}^{N} \delta_{m} T_{m} y, j(x-y)\right\rangle \\
& =\beta_{n}\langle T x-T y, j(x-y)\rangle \\
& \leq \beta_{n}\left(\|x-y\|^{2}-\lambda\|(I-T) x-(I-T) y\|^{2}\right) \\
& \leq \beta_{n}\|x-y\| .
\end{aligned}
$$

This shows that $P_{n}$ is strongly pseudocontractive. Since strictly pseudocontractive mappings are Lipschitz continuous, we see that $P_{n}$ is also continuous. In view of Lemma 1.1, we see that $P_{n}$ has a unique fixed point. This proves that the implicit iterative algorithm (2.1) 
is well defined. In view of Lemma 1.2, we see that $F=F\left(\sum_{m=1}^{N} \delta_{m} F\left(T_{m}\right)\right)=F(T)$. Fixing $p \in F$, we see that

$$
\begin{aligned}
\left\|x_{n}-p\right\|^{2} & =\alpha_{n}\left\langle x_{n-1}-p, j(x-p)\right\rangle+\beta_{n}\left\langle\sum_{m=1}^{N} \delta_{m} T_{m} x_{n}-p, j(x-y)\right\rangle+\gamma_{n}\left\langle u_{n}-p, j(x-y)\right\rangle \\
& =\alpha_{n}\left\langle x_{n-1}-p, j(x-p)\right\rangle+\beta_{n}\left\langle T x_{n}-p, j(x-p)\right\rangle+\gamma_{n}\left\langle u_{n}-p, j(x-p)\right\rangle \\
& \leq \alpha_{n}\left\|x_{n-1}-p\right\|\|x-p\|+\beta_{n}\|x-p\|^{2}-\beta_{n} \lambda\left\|x_{n}-T x_{n}\right\|^{2}+\gamma_{n}\left\|u_{n}-p\right\|\|x-p\| .
\end{aligned}
$$

It follows that

$$
\left\|x_{n}-p\right\| \leq \alpha_{n}\left\|x_{n-1}-p\right\|+\beta_{n}\left\|x_{n}-p\right\|-\beta_{n} \lambda\left\|x_{n}-T x_{n}\right\|^{2}+\gamma_{n}\left\|u_{n}-p\right\| .
$$

This implies, from the restriction (c), that

$$
\left\|x_{n}-p\right\| \leq\left\|x_{n-1}-p\right\|+\gamma_{n} M-\beta_{n} \lambda\left\|x_{n}-T x_{n}\right\|^{2},
$$

where $M$ is an appropriate constant such that $M \geq \sup _{n \geq 1}\left\{\frac{\left\|u_{n}-p\right\|}{a}\right\}$. In view of Lemma 1.3, we obtain that $\lim _{n \rightarrow \infty}\left\|x_{n}-p\right\|$ exits. Thanks to (2.2), we find from the restrictions (b) and (c) that

$$
\lim _{n \rightarrow \infty}\left\|x_{n}-T x_{n}\right\|=0
$$

Since the space is reflexive and $\left\{x_{n}\right\}$ is bounded, there exists a subsequence $\left\{x_{n_{i}}\right\}$ of the sequence $\left\{x_{n}\right\}$, which weakly converges to some $x \in$. In view of Lemma 1.4, we find that $x \in F(T)=F$.

Finally, we show the sequence $\left\{x_{n}\right\}$ weakly converges to $x$. Suppose the contrary, then there exists some subsequence $\left\{x_{n_{j}}\right\}$ of the sequence $\left\{x_{n}\right\}$ which weakly converges to $x^{\prime} \neq$ $x \in C$. It also follows from Lemma 1.4 that $x^{\prime} \in F$. Since $\lim _{n \rightarrow \infty}\left\|x_{n}-p\right\|$ exits for any $p \in F$. Put

$$
\lim _{n \rightarrow \infty}\left\|x_{n}-x\right\|=d, \quad \lim _{n \rightarrow \infty}\left\|x_{n}-x^{\prime}\right\|=d^{\prime} .
$$

Since the space satisfies Opial's condition, we see that

$$
\begin{aligned}
d & =\lim _{n \rightarrow \infty}\left\|x_{n}-x\right\| \\
& =\liminf _{i \rightarrow \infty}\left\|x_{n_{i}}-x\right\| \\
& <\liminf _{i \rightarrow \infty}\left\|x_{n_{i}}-x^{\prime}\right\| \\
& =\lim _{n \rightarrow \infty}\left\|x_{n}-x^{\prime}\right\| \\
& =\liminf _{j \rightarrow \infty}\left\|x_{n_{j}}-x^{\prime}\right\| \\
& <\liminf _{j \rightarrow \infty}\left\|x_{n_{j}}-x\right\| \\
& =\lim _{n \rightarrow \infty}\left\|x_{n}-x\right\|=d .
\end{aligned}
$$


This is a contradiction. This shows that $x=x^{\prime}$. This proves that the sequence $\left\{x_{n}\right\}$ converges weakly to $x \in F$. This completes the proof.

Corollary 2.2 Let $E$ be a smooth and reflexive Banach space which also satisfies Opial's condition and let $K$ be a nonempty closed convex subset of $E$. Let $N \geq 1$ be some positive integer. Let $T_{m}: K \rightarrow K$, where $m \in\{1, \ldots, N\}$, be a $\lambda_{i}$-strictly pseudocontractive mapping. Let $\left\{x_{n}\right\}_{n=0}^{\infty}$ be a sequence generated in the following algorithm:

$$
x_{0} \in K, \quad x_{n}=\alpha_{n} x_{n-1}+\left(1-\alpha_{n}\right) \sum_{m=1}^{N} \delta_{m} T_{m} x_{n}, \quad n \geq 1,
$$

where $\left\{\alpha_{n}\right\}$ and $\left\{\delta_{m}\right\}$ are real number sequences in $[0,1]$. Assume that $F:=\bigcap_{m=1}^{N} F\left(T_{m}\right) \neq \emptyset$ and the above control sequences satisfy the following restrictions:

(a) $\sum_{m=1}^{N} \delta_{m}=1$;

(b) $0<a \leq \alpha_{n} \leq b<1$, where $a$ and $b$ are constants.

Then $\left\{x_{n}\right\}$ converges weakly to some point in $F$.

In Hilbert spaces, we find from Theorem 2.1 the following.

Corollary 2.3 Let $E$ be a Hilbert space and $K$ be a nonempty closed convex subset of $E$. Let $N \geq 1$ be some positive integer. Let $T_{m}: K \rightarrow K$, where $m \in\{1, \ldots, N\}$, be a $\lambda_{i}$-strictly pseudocontractive mapping and $\left\{u_{n}\right\}$ be a bounded sequence in $K$. Let $\left\{x_{n}\right\}_{n=0}^{\infty}$ be a sequence generated in the following algorithm:

$$
x_{0} \in K, \quad x_{n}=\alpha_{n} x_{n-1}+\beta_{n} \sum_{m=1}^{N} \delta_{m} T_{m} x_{n}+\gamma_{n} u_{n}, \quad n \geq 1,
$$

where $\left\{\alpha_{n}\right\},\left\{\beta_{n}\right\},\left\{\gamma_{n}\right\}$, and $\left\{\delta_{m}\right\}$ are real number sequences in $[0,1]$. Assume that $F:=$ $\bigcap_{m=1}^{N} F\left(T_{m}\right) \neq \emptyset$ and the above control sequences satisfy the following restrictions:

(a) $\sum_{m=1}^{N} \delta_{m}=\alpha_{n}+\beta_{n}+\gamma_{n}=1$;

(b) $\sum_{n=1}^{\infty} \gamma_{n}<\infty$;

(c) $0<a \leq \alpha_{n} \leq b<1$, where $a$ and $b$ are constants.

Then $\left\{x_{n}\right\}$ converges weakly to some point in $F$.

Next, we give a strong convergence theorem.

Theorem 2.4 Let $E$ be a smooth and reflexive Banach space and $K$ be a nonempty closed convex subset of E. Let $N \geq 1$ be some positive integer. Let $T_{m}: K \rightarrow K$, where $m \in\{1, \ldots, N\}$, be a $\lambda_{i}$-strictly pseudocontractive mapping and $\left\{u_{n}\right\}$ be a bounded sequence in $K$. Let $\left\{x_{n}\right\}_{n=0}^{\infty}$ be a sequence generated in the following algorithm:

$$
x_{0} \in K, \quad x_{n}=\alpha_{n} x_{n-1}+\beta_{n} \sum_{m=1}^{N} \delta_{m} T_{m} x_{n}+\gamma_{n} u_{n}, \quad n \geq 1,
$$

where $\left\{\alpha_{n}\right\},\left\{\beta_{n}\right\},\left\{\gamma_{n}\right\}$, and $\left\{\delta_{m}\right\}$ are real number sequences in $[0,1]$. Assume that $F:=$ $\bigcap_{m=1}^{N} F\left(T_{m}\right) \neq \emptyset$ and the above control sequences satisfy the following restrictions:

(a) $\sum_{m=1}^{N} \delta_{m}=\alpha_{n}+\beta_{n}+\gamma_{n}=1$; 
(b) $\sum_{n=1}^{\infty} \gamma_{n}<\infty$;

(c) $0<a \leq \alpha_{n} \leq b<1$, where $a$ and $b$ are constants.

If $\sum_{m=1}^{N} \delta_{m} T_{m}$ is semicompact, then $\left\{x_{n}\right\}$ converges strongly to some point in $F$.

Proof Since $\sum_{m=1}^{N} \delta_{m} T_{m}$ is semicompact, we see that there exists a subsequence $\left\{x_{n_{i}}\right\}$ of $\left\{x_{n}\right\}$ such that $x_{n_{i}} \rightarrow x^{*}$. Notice that

$$
\begin{aligned}
\left\|x^{*}-\sum_{m=1}^{N} \delta_{m} T_{m} x^{*}\right\| \leq & \left\|x^{*}-x_{n_{i}}\right\|+\left\|x_{n_{i}}-\sum_{m=1}^{N} \delta_{m} T_{m} x_{n_{i}}\right\| \\
& +\left\|\sum_{m=1}^{N} \delta_{m} T_{m} x_{n_{i}}-\sum_{m=1}^{N} \delta_{m} T_{m} x_{n_{i}} x^{*}\right\| .
\end{aligned}
$$

Since $\sum_{m=1}^{N} \delta_{m} T_{m}$ is Lipschitz continuous, we see from (2.3) that $x^{*} \in F\left(\sum_{m=1}^{N} \delta_{m} T_{m}\right)=F$. From Theorem 2.1, we know that $\lim _{n \rightarrow \infty}\left\|x_{n}-p\right\|$ exits for any $p \in F$. That is, $\lim _{n \rightarrow \infty} \| x_{n}-$ $x^{*} \|$ exits. In view of $x_{n_{i}} \rightarrow x^{*}$, we find that

$$
\lim _{n \rightarrow \infty}\left\|x_{n}-x^{*}\right\|=0
$$

This completes the proof.

Corollary 2.5 Let E be a smooth and reflexive Banach space and $K$ be a nonempty closed convex subset of E. Let $N \geq 1$ be some positive integer. Let $T_{m}: K \rightarrow K$, where $m \in\{1, \ldots, N\}$, be a $\lambda_{i}$-strictly pseudocontractive mapping. Let $\left\{x_{n}\right\}_{n=0}^{\infty}$ be a sequence generated in the following algorithm:

$$
x_{0} \in K, \quad x_{n}=\alpha_{n} x_{n-1}+\left(1-\alpha_{n}\right) \sum_{m=1}^{N} \delta_{m} T_{m} x_{n}, \quad n \geq 1,
$$

where $\left\{\alpha_{n}\right\}$ and $\left\{\delta_{m}\right\}$ are real number sequences in $[0,1]$. Assume that $F:=\bigcap_{m=1}^{N} F\left(T_{m}\right) \neq \emptyset$ and the above control sequences satisfy the following restrictions:

(a) $\sum_{m=1}^{N} \delta_{m}=1$;

(b) $0<a \leq \alpha_{n} \leq b<1$, where $a$ and $b$ are constants.

If $\sum_{m=1}^{N} \delta_{m} T_{m}$ is semicompact, then $\left\{x_{n}\right\}$ converges strongly to some point in $F$.

In Hilbert spaces, we find from Theorem 2.1 the following.

Corollary 2.6 Let $E$ be a Hilbert space and $K$ be a nonempty closed convex subset of $E$. Let $N \geq 1$ be some positive integer. Let $T_{m}: K \rightarrow K$, where $m \in\{1, \ldots, N\}$, be a $\lambda_{i}$-strictly pseudocontractive mapping and $\left\{u_{n}\right\}$ be a bounded sequence in K. Let $\left\{x_{n}\right\}_{n=0}^{\infty}$ be a sequence generated in the following algorithm:

$$
x_{0} \in K, \quad x_{n}=\alpha_{n} x_{n-1}+\beta_{n} \sum_{m=1}^{N} \delta_{m} T_{m} x_{n}+\gamma_{n} u_{n}, \quad n \geq 1,
$$

where $\left\{\alpha_{n}\right\},\left\{\beta_{n}\right\},\left\{\gamma_{n}\right\}$, and $\left\{\delta_{m}\right\}$ are real number sequences in $[0,1]$. Assume that $F:=$ $\bigcap_{m=1}^{N} F\left(T_{m}\right) \neq \emptyset$ and the above control sequences satisfy the following restrictions: 
(a) $\sum_{m=1}^{N} \delta_{m}=\alpha_{n}+\beta_{n}+\gamma_{n}=1$;

(b) $\sum_{n=1}^{\infty} \gamma_{n}<\infty$;

(c) $0<a \leq \alpha_{n} \leq b<1$, where $a$ and $b$ are constants.

If $\sum_{m=1}^{N} \delta_{m} T_{m}$ is semicompact, then $\left\{x_{n}\right\}$ converges strongly to some point in $F$.

\section{Competing interests}

The authors declare that they have no competing interests.

\section{Author details}

'Department of Mathematics, Renai College of Tianjin University, Tianjin, 301636, China. ${ }^{2}$ Department of Mathematics, Hangzhou Normal University, Hangzhou, China. ${ }^{3}$ Department of Mathematics, Henan University, Kaifeng, China.

\section{Acknowledgements}

The authors are grateful to the reviewers' suggestions which improved the contents of the article.

Received: 17 September 2012 Accepted: 25 January 2013 Published: 28 February 2013

\section{References}

1. Browder, FE, Petryshyn, WV: Construction of fixed points of nonlinear mappings in Hilbert spaces. J. Math. Anal. Appl. 20, 197-228 (1967)

2. Browder, FE: Nonlinear Operators and Nonlinear Equations of Evolution in Banach Spaces. Proc. Sympos. Math., vol. 18. Am. Math. Soc., Providence (1976)

3. Zhou, $\mathrm{H}$ : Convergence theorems of common fixed points for a finite family of Lipschitz pseudocontractions in Banach spaces. Nonlinear Anal. 68, 2977-2983 (2008)

4. Chidume, CE, Mutangadura, SA: An example on the Mann iteration method for Lipschitz pseudo-contractions. Proc. Am. Math. Soc. 129, 2359-2363 (2001)

5. Xu, HK, Ori, RG: An implicit iteration process for nonexpansive mappings. Numer. Funct. Anal. Optim. 22, 767-773 (2001)

6. Osilike, MO: Implicit iteration process for common fixed points of a finite family of strictly pseudocontractive maps. J. Math. Anal. Appl. 294, 73-81 (2004)

7. Cho, SY, Kang, SM: Approximation of fixed points of pseudocontraction semigroups based on a viscosity iterative process. Appl. Math. Lett. 24, 224-228 (2011)

8. Cho, SY, Qin, X, Kang, SM: Hybrid projection algorithms for treating common fixed points of a family of demicontinuous pseudocontractions. Appl. Math. Lett. 25, 854-857 (2012)

9. Zhou, $\mathrm{H}$ : Convergence theorems for $\lambda$-strict pseudo-contractions in 2-uniformly smooth Banach spaces. Nonlinear Anal. 69, 3160-3173 (2008)

10. Qin, $X$, Cho, SY, Kang, SM: Strong convergence of shrinking projection methods for quasi- $\phi$-nonexpansive mappings and equilibrium problems. J. Comput. Appl. Math. 234, 750-760 (2010)

11. Zhou, $\mathrm{H}$ : Convergence theorems of common fixed points for a finite family of Lipschitz pseudocontractions in Banach spaces. Nonlinear Anal. 68, 2977-2983 (2008)

12. Cho, SY, Kang, SM: Approximation of common solutions of variational inequalities via strict pseudocontractions. Acta Math. Sci. 32, 1607-1618 (2012)

13. Kim, JK, Nam, YM, Sim, JY: Convergence theorems of implicit iterative sequences for a finite family of asymptotically quasi-nonexpansive type mappings. Nonlinear Anal. 71, e2839-e2848 (2009)

14. Qin, X, Cho, YJ, Kang, SM: Convergence theorems of common elements for equilibrium problems and fixed point problems in Banach spaces. J. Comput. Appl. Math. 225, 20-30 (2009)

15. Luo, H, Wang, Y: Iterative approximation for the common solutions of a infinite variational inequality system for inverse-strongly accretive mappings. J. Math. Comput. Sci. 2, 1660-1670 (2012)

16. Qin, X, Cho, SY, Kang, SM: An extragradient-type method for generalized equilibrium problems involving strictly pseudocontractive mappings. J. Glob. Optim. 49, 679-693 (2012)

17. Zegeye, $\mathrm{H}$, Shahzad, N: Strong convergence theorem for a common point of solution of variational inequality and fixed point problem. Adv. Fixed Point Theory 2, 374-397 (2012)

18. Lv, S, Wu, C: Convergence of iterative algorithms for a generalized variational inequality and a nonexpansive mapping. Eng. Math. Lett. 1, 44-57 (2012)

19. Qin, X, Cho, SY, Kang, SM: On hybrid projection methods for asymptotically quasi- $\boldsymbol{\phi}$-nonexpansive mappings. Appl. Math. Comput. 215, 3874-3883 (2010)

20. Qing, Y, Kim, JK: Weak convergence of algorithms for asymptotically strict pseudocontractions in the intermediate sense and equilibrium problems. Fixed Point Theory Appl. 2012, Article ID 132 (2012)

21. Ye, J, Huang, J: Strong convergence theorems for fixed point problems and generalized equilibrium problems of three relatively quasi-nonexpansive mappings in Banach spaces. J. Math. Comput. Sci. 1, 1-18 (2011)

22. Hao, H, Wang, X, Tong, A: Weak and strong convergence theorems for two finite families of asymptotically nonexpansive mappings in Banach spaces. Adv. Fixed Point Theory 2, 417-432 (2012)

23. Qin, X, Shang, M, Su, Y: Strong convergence of a general iterative algorithm for equilibrium problems and variational inequality problems. Math. Comput. Model. 48, 1033-1046 (2008)

24. Kim, JK, Cho, SY, Qin, X: Hybrid projection algorithms for generalized equilibrium problems and strictly pseudocontractive mappings. J. Inequal. Appl. 2010, Article ID 312602 (2010)

25. Osilike, MO, Shehu, Y: Explicit averaging cyclic algorithm for common fixed points of a finite family of asymptotically strictly pseudocontractive maps in Banach spaces. Comput. Math. Appl. 57, 1502-1510 (2009) 
26. Kim, JK, Cho, SY, Qin, X: Some results on generalized equilibrium problems involving strictly pseudocontractive mappings. Acta Math. Sci. 31, 2041-2057 (2011)

27. Acedo, GL, Xu, HK: Iterative methods for strict pseudo-contractions in Hilbert spaces. Nonlinear Anal. 67, 2258-2271 (2007)

28. Qin, X, Cho, YJ, Kang, SM, Zhou, H: Convergence of a modified Halpern-type iteration algorithm for quasi- $\phi$-nonexpansive mappings. Appl. Math. Lett. 22, 1051-1055 (2009)

29. Kim, JK: Strong convergence theorems by hybrid projection methods for equilibrium problems and fixed point problems of the asymptotically quasi- $\boldsymbol{\phi}$-nonexpansive mappings. Fixed Point Theory Appl. 2011, Article ID 10 (2011)

30. Kim, JK, Anah, PN, Nam, YM: Strong convergence of an extended extragradient method for equilibrium problems and fixed point problems. J. Korean Math. Soc. 49, 187-200 (2012)

31. Cho, SY, Kang, SM: Zero point theorems for $m$-accretive operators in a Banach space. Fixed Point Theory Appl. 13, 49-58 (2012)

32. Kang, SM, Cho, SY, Liu, Z: Generalized equilibrium problems involving inverse-strongly monotone mappings. J. Inequal. Appl. 2010, Article ID 827082 (2010)

33. Opial, Z: Weak convergence of the sequence of successive approximation for nonexpansive mappings. Bull. Am. Math. Soc. 73, 591-597 (1967)

34. Deimling, K: Zeros of accretive operators. Manuscr. Math. 13, 365-374 (1974)

35. Tan, KK, Xu, HK: Approximating fixed points of nonexpansive mappings by the Ishikawa iterative process. J. Math. Anal. Appl. 178, 301-308 (1993)

doi:10.1186/1029-242X-2013-74

Cite this article as: Yang et al.: Some results on parallel iterative algorithms for strictly pseudocontractive mappings. Journal of Inequalities and Applications 2013 2013:74.

\section{Submit your manuscript to a SpringerOpen ${ }^{\circ}$ journal and benefit from:}

- Convenient online submission

- Rigorous peer review

- Immediate publication on acceptance

Open access: articles freely available online

- High visibility within the field

- Retaining the copyright to your article 